\title{
Does a full bladder assist insertion of intrauterine contraception? A randomised trial
}

\author{
Sharon T Cameron, ${ }^{1}$ Anna Glasier, ${ }^{2}$ Amy Cooper, ${ }^{3}$ Anne Johnstone ${ }^{4}$
}

\begin{abstract}
${ }^{1}$ Consultant Gynaecologist, Chalmers Sexual and Reproductive Health Centre, Edinburgh, UK

${ }^{2}$ Professor, Department of Reproductive and Developmental Sciences, Obstetrics and Gynaecology, University of Edinburgh, Royal Infirmary of Edinburgh, Edinburgh, UK ${ }^{3}$ Medical Student, University of Edinburgh, College of Medicine and Veterinary Medicine, Edinburgh, UK

${ }^{4}$ Clinical Research Nurse, Department of Reproductive and Developmental Sciences, Obstetrics and Gynaecology, University of Edinburgh, Royal Infirmary of Edinburgh, Edinburgh, UK
\end{abstract}

\section{Correspondence to} Dr Sharon Cameron, Chalmers Sexual and Reproductive Health Centre, 2a Chalmers Street, Edinburgh EH3 9ES, UK;sharon. cameron@ed.ac.uk

Received 3 July 2012 Accepted 6 November 2012 Published Online First 24 January 2013
To cite: Cameron ST, Glasier A, Cooper A, et al. I Fam Plann Reprod Health Care 2013;39:207-210.

\begin{abstract}
Background Bladder distension is thought to cause the uterine axis to become more aligned with the cervical canal. Among women undergoing assisted conception it has been demonstrated that having a full bladder facilitates the passage of an intrauterine catheter for embryo transfer.

Objective To determine if insertion of intrauterine contraceptive devices is easier in women who have a full bladder at the time of insertion.
\end{abstract}

Methods 200 women requesting intrauterine contraception with a pre-filled bladder were randomised to delayed emptying (after insertion; $n=100$ ) or immediate emptying (before insertion; $n=100$ ). Comparisons were made between doctors' reported ease of insertion and women's pain scores.

Results There was no significant difference with reported ease of insertion between the groups.

Doctors reported that insertions were either 'very easy' or 'quite easy' in $82 \%$ and $83 \%$ of women in the immediate and delayed emptying groups, respectively (95\% Cls for difference $-10 \%$ to $+11 \%)$. There was no significant difference in reported pain scores, with mean pain scores (out of 10) of 3.8 and 4.4 in the delayed and immediate emptying groups, respectively. Conclusions Bladder filling does not have a significant effect on ease of insertion of an intrauterine method of contraception. Insertion is mostly associated with low levels of discomfort, even in the presence of a full bladder.

\section{INTRODUCTION}

In spite of the intrauterine device (IUD) and intrauterine system (IUS) being among the most effective methods of contraception, data from the UK show that only $8 \%$ of women of reproductive age used intrauterine contraception in 2009. ${ }^{1}$ Myths and misconceptions about intrauterine methods reportedly deter

\section{KEY MESSAGE POINTS}

- The presence or absence of urine in the bladder does not have a significant effect on ease of insertion of an intrauterine method of contraception.

- Insertion of an intrauterine device (IUD) or intrauterine system (IUS) is mostly associated with low levels of discomfort, even in the presence of a full bladder.

- There is no need for women to routinely empty their bladders before IUD/IUS insertion.

many women from using them. ${ }^{2}{ }^{3}$ Many women who choose an intrauterine method are worried about the discomfort of having the device inserted. ${ }^{3}$ Interventions tested to reduce pain during insertion have included use of nonsteroidal anti-inflammatory drugs, local anaesthesia to the cervix, and cervical ripening using misoprostol. However, most of these interventions have proved ineffective. $^{4-8}$

There is good evidence from in vitro fertilisation (IVF) procedures that if women have a full bladder at the time of intrauterine embryo transfer (ET) then the transfer catheter is passed more easily than when the bladder is empty. ${ }^{9}$ It is thought that bladder distension causes the uterine axis to become more aligned with the cervical canal. ${ }^{10}$ It is possible that having a full bladder - a simple, free, non-pharmacological intervention - could similarly make passage of an IUD/IUS easier. The aim of this study was to determine if having a full bladder at the time of insertion of an intrauterine contraceptive method was associated with greater ease of insertion than having an empty bladder. We also wished to determine if this was, in turn, associated with less or greater discomfort for the woman. 


\section{METHODS}

The study took place at a family planning clinic in the centre of Edinburgh, Scotland, UK between March 2009 and March 2011. Women who wished to have an intrauterine method of contraception routinely attended a clinic for counselling about the method by a clinician, before being given an appointment for subsequent insertion of the device. Women were given verbal and written information about the study and were advised that if they wished to participate they should attend for IUD/IUS insertion with a full bladder. Women were advised that to ensure a full bladder they should drink one litre (or six glasses) of fluid in the hour before the appointment. There were no other inclusion or exclusion criteria.

The doctor who was performing the IUD/IUS insertion asked only those women who had complied with bladder filling if they still wished to participate in the study. Participants gave written, informed consent and were then randomised to either immediate or delayed bladder emptying. Randomisation was conducted in blocks of ten using a computer-generated sequence. The study intervention to which women were allocated was determined by opening a sequentially numbered opaque sealed envelope, inside which were printed the words 'Empty now' or 'Keep filled'.

Women randomised to 'immediate emptying' were instructed to go to the toilet immediately prior to IUD/IUS insertion. Women randomised to 'delayed emptying' did this only after the IUD/IUS insertion had been conducted. In keeping with guidance from the Clinical Effectiveness Unit of the Faculty of Sexual and Reproductive Healthcare, a bimanual examination was conducted as a standard procedure and a tenaculum applied to the cervix. ${ }^{11}$

Immediately after IUD/IUS insertion (and before bladder emptying if applicable) women were asked to indicate how much discomfort they had experienced during the procedure on a 10 -point scale where 0 corresponded to no pain and 10 corresponded to agony. Women in the delayed emptying group were then asked to urinate into a container. The volume of urine passed was measured by the clinic nurse.

Doctors $(n=12)$ who conducted the procedure ranked the ease of insertion of the device on a fivepoint Likert scale from 'very easy' to 'very difficult'. This was recorded on the study proforma together with details of the woman's parity, pre-procedure use of analgesia and any local anaesthesia administered during the insertion.

\section{Statistical methods}

A sample size calculation suggested that 100 subjects in each arm would give $80 \%$ power for a two-sided test at the 5\% significance level to detect a difference between 90\% easy insertions with empty bladder (immediate emptying) and 99\% easy insertions with a filled bladder (delayed emptying). Data were entered into a database using Microsoft Excel and statistical analysis was performed on coded data using IBM Statistical Package for the Social Sciences (SPSS) software version 17 (SPSS Inc., Chicago, IL, USA). Groups were compared by chi-square $\left(\chi^{2}\right)$ tests or $t$-tests, and Spearman rank correlation or KruskalWallis tests were used to assess which factors predicted ease of insertion.

\section{RESULTS}

Two hundred women were recruited and 100 women were randomised to each study arm. The demographic characteristics of women in each group were similar (Table 1). Insertion of an intrauterine method did not take place in four women. Reasons for failure to insert in the delayed emptying group $(n=3)$ were due to cervical stenosis $(n=1)$, inability to remove an existing IUS that was still in situ $(n=1)$ and a suspected perforation at uterine sounding $(n=1)$. The one case of failure to insert in the immediate emptying group was due to the woman feeling unwell after uterine sounding.

\section{Ease of insertion}

There was no significant difference between groups with reported ease of insertion (Table 2). Doctors reported that insertions were either 'very easy' or 'quite easy' in $82 \%$ and $83 \%$ of women in the immediate and delayed emptying groups, respectively [95\% confidence intervals (CI) for the difference $-10 \%$ to $+11 \%)$. For women in the delayed emptying group, the mean (standard deviation) volume of urine passed

Table 1 Comparison of patient characteristics in those with delayed and immediate bladder emptying

\begin{tabular}{|c|c|c|}
\hline Factor & $\begin{array}{l}\text { Delayed } \\
\text { emptying } \\
(n=100)\end{array}$ & $\begin{array}{l}\text { Immediate } \\
\text { emptying } \\
(n=100)\end{array}$ \\
\hline Age range (years) & $19-50$ & $20-52$ \\
\hline Mean (SD) & $33.5(8.2)$ & $33.8(8.6)$ \\
\hline \multicolumn{3}{|l|}{ Reproductive history } \\
\hline Nulliparous & 41 & 45 \\
\hline Parous & 59 & 55 \\
\hline Previous vaginal birth & 49 & 46 \\
\hline $\begin{array}{l}\text { Had previous colposcopic } \\
\text { treatment }\end{array}$ & 12 & 11 \\
\hline \multicolumn{3}{|l|}{ Device inserted } \\
\hline Mirena ${ }^{\circledR}$ & 52 & 67 \\
\hline Slimline TT380 ${ }^{\circledR}$ & 19 & 7 \\
\hline Nova $T 380^{\circledR}$ & 10 & 15 \\
\hline Multiload $375^{\circledR}$ & 1 & 0 \\
\hline UT $380^{\circledR}$ & 13 & 9 \\
\hline Mini TT $380^{\circledR}$ & 1 & 1 \\
\hline Other IUD & 1 & 0 \\
\hline None* & 3 & 1 \\
\hline
\end{tabular}

* Devices could not be inserted in four women.

IUD, intrauterine device; SD, standard deviation. 
Table 2 Comparison of outcomes in women who had intrauterine method inserted with delayed $(n=97)$ and immediate $(n=99)$ emptying of bladders

\begin{tabular}{|c|c|c|c|}
\hline Factor & $\begin{array}{l}\text { Delayed } \\
\text { empting } \\
(n=97)\end{array}$ & $\begin{array}{l}\text { Immediate } \\
\text { emptying } \\
(n=99)\end{array}$ & $p$ \\
\hline \multicolumn{4}{|l|}{ Analgesics } \\
\hline None & 41 & 31 & 0.30 \\
\hline Paracetamol & 21 & 21 & \\
\hline NSAID & 24 & 30 & \\
\hline Paracetamol+NSAID & 4 & 10 & \\
\hline Other & 7 & 7 & \\
\hline Pain score [mean (SD)] & $3.8(2.3)$ & $4.4(2.3)$ & 0.10 \\
\hline $\begin{array}{l}\text { Had cervical local } \\
\text { anaesthesia }\end{array}$ & 60 & 51 & 0.25 \\
\hline \multicolumn{4}{|l|}{ Doctor's ease of insertion } \\
\hline Very easy & 50 & 51 & 0.68 \\
\hline Quite easy & 32 & 32 & \\
\hline Neither & 3 & 10 & \\
\hline Quite difficult & 12 & 6 & \\
\hline Very difficult & 0 & 0 & \\
\hline
\end{tabular}

NSAID, non-steroidal anti-inflammatory drug; SD, standard deviation.

at the end of the procedure was 346 (212) $\mathrm{ml}$. For women who passed a volume of at least $250 \mathrm{ml}$ urine $(n=60)$, insertion was reported as 'very' or 'quite easy' in $86 \%$ compared to $82 \%$ for those with volumes of less than $250 \mathrm{ml}(p=0.92)$. Of the factors in Table 1 , only parity showed a significant association $(p<0.05)$ with doctors' ease of insertion assessments, with $97(88 \%)$ of insertions found to be 'very' or 'quite' easy in parous women, as compared to 68 (79\%) in those who were nulliparous. There was no difference in ease of insertion between groups with type of device (IUD or IUS).

\section{Pain of insertion}

A total of 126 (63\%) women had taken pre-insertion oral analgesia. There were no significant differences between groups in the proportions of women using pre-procedure analgesia or receiving intracervical local anaesthesia during the procedure (Table 2.)

There was no significant difference between groups in reported pain, with mean pain scores (out of 10) of 3.8 and 4.4 for the procedure in women randomised to the delayed and immediate emptying groups, respectively (Table 2 ).

\section{DISCUSSION}

This study demonstrated that presence or absence of urine in the bladder did not have a significant effect on ease of insertion of an intrauterine method of contraception. Furthermore, the presence or absence of urine in the bladder did not affect reported discomfort during insertion. We had hypothesised that bladder filling would align the axis of the uterus and cervical canal and render insertion easier, as this has been demonstrated for ET for IVF. ${ }^{9} 1012$ Clearly, however, the catheters used for ET are much finer and more flexible than introducers for either the IUD or IUS. Another difference between ET and IUD/IUS insertion is that the application of a tenaculum to the cervix is generally avoided at ET, whereas this is recommended as routine at IUD/IUS insertion. ${ }^{11}$ It is possible therefore that traction upon the tenaculum at IUD/IUS insertion may have had the effect that bladder filling alone, in the absence of a tenaculum, has at ET. It is also possible that the degree of bladder filling achieved in our study was not sufficiently great for us to detect an effect. Although the average volume of urine passed in our study was above the limit that is often accepted as the 'full' volume that stimulates a desire to micturate $(150-200 \mathrm{ml}),{ }^{13}$ this was still much less than the bladder volume $(500 \mathrm{ml})$ that was associated with a positive effect on ease of ET. ${ }^{9} 1012$ It is also possible that there were insufficient numbers of women in the 'delayed emptying' arm with a sufficiently filled bladder to detect a difference. Undoubtedly the motivation to drink sufficient fluid for a full bladder may be different between women who would do anything to maximise the success of IVF in the hope of becoming pregnant and women attending for IUD/IUS insertion. Furthermore, in the majority of cases in our study, IUD/IUS insertion was reported to be an easy procedure.

It is of course possible that bladder filling might be helpful in individual cases such as in women with a markedly retroverted or anteverted uterus, where alignment of the angle between the uterine axis and the cervical canal may be more difficult to achieve than by tenaculum traction alone. It has previously been shown that that retroversion of the uterus is a factor associated with failure of endometrial ablation, another gynaecological procedure requiring uterine instrumentation. ${ }^{14} 15$ One could hypothesise therefore that having a full bladder could potentially facilitate uterine instrumentation or passage of an IUD/IUS into a markedly retroverted or anteverted uterus. Unfortunately our study design did not permit us to test this hypothesis.

The only factor that was shown to be associated with ease of insertion in our study was parity, with easier insertions reported for parous women. However, this ease of insertion was not reflected in reported pain scores, with similar scores reported by both parous and nulliparous women in our study and in previous studies. ${ }^{16}$ Given that worries about discomfort during the procedure deter women from considering an intrauterine method, clinicians may find it helpful when counselling women about this method to reassure them that in this study at least 8 out of 10 of all insertions were considered easy and that the overall average reported discomfort (i.e. pain score) associated with having an IUD/IUS inserted was only 4 out of 10 .

It is clear that the design of our study had several limitations. For practical reasons, we chose to 
randomise women at the insertion visit, asking all those who were keen to participate to attend with a full bladder. We do not know how many women were deterred from participating for this reason, or indeed for any other reason. Furthermore, the duration of time between intake of the requested volume of fluid and IUD/IUS insertion was not standardised, which may have impacted upon bladder filling. It is possible that if we had been able to randomise volunteers at the initial clinic assessment visit, then women who knew that they were in the 'full bladder' arm may have made a concerted effort to drink larger volumes of fluid. Furthermore, doctors in our study were not blinded to study randomisation, but we felt that this would not have been possible since doctors might have been able to palpate a full bladder during bimanual examination. Finally, insertions were carried out by a group of 12 clinicians, which may also potentially introduce bias to the results.

In conclusion, therefore, unlike ET transfer, bladder filling does not facilitate insertion of an IUD/IUS. Although some clinicians might worry that the presence of a full bladder might make it more difficult for them to conduct a bimanual examination or to determine uterine position, there did not appear to be an obvious disadvantage for either the clinicians (in terms of ease of insertion) or for women (discomfort with insertion) with the presence of urine in the bladder at insertion. This at least indicates that clinicians should not insist that women empty their bladders before having an IUD/IUS fitted.

Acknowledgements The authors are grateful to Dr Rob Elton (Statistician and Honorary Fellow, University of Edinburgh) for statistical expertise and to the staff of the Chalmers Centre who assisted with this study.

Funding None.

Competing interests None.

Ethics approval South East Scotland Research Ethics Committee (REC 08/S1102/30).

Provenance and peer review Not commissioned; externally peer reviewed.

\section{REFERENCES}

1 Lader D. Opinions Survey Report No. 41. Contraception and Sexual Health 2008/09. 2009. http://www.ons.gov.uk/ons/rel/ lifestyles/contraception-and-sexual-health/2008-09/2008-09. pdf [accessed 5 October 2012].
2 Glasier A, Scorer J, Bigrigg A. Attitudes of women in Scotland to contraception: a qualitative study to explore the acceptability of long-acting methods. J Fam Plann Reprod Health Care 2008;34:213-217.

3 Asker C, Stokes-Lampard H, Beaven J, et al. What is it about intrauterine devices that women find unacceptable? Factors that make women non-users: a qualitative study. J Fam Plann Reprod Health Care 2006;32:89-94.

4 Allen RH, Bartz D, Grimes DA, et al. Interventions for pain with intrauterine device insertion. Cochrane Database Syst Rev 2009;3:CD007373.

5 Saav I, Aronsson A, Marions L, et al. Cervical priming with sublingual misoprostol prior to insertion of an intrauterine device in nulliparous women: a randomized controlled trial. Hum Reprod 2007;22:2647-2652.

6 Maguire K, Davis A, Rosario Tejeda L, et al. Intracervical lidocaine gel for intrauterine device insertion: a randomized controlled trial. Contraception 2012;86:214-219.

7 Edelman AB, Schaefer E, Olson A, et al. Effects of prophylactic misoprostol administration prior to intrauterine device insertion in nulliparous women. Contraception 2011;84: 234-239.

8 Dijkhuizen K, Dekkers OM, Holleboom CA, et al. Vaginal misoprostol prior to insertion of an intrauterine device: an RCT. Hum Reprod 2011;26:323-329.

9 Abou-Setta AM. Effect of passive uterine straightening during embryo transfer: a systematic review and meta-analysis. Acta Scan 2007;86:516-522.

10 Lewin A, Schenker JG, Avrech O, et al. The role of uterine straightening by passive bladder distension before embryo transfer in IVF cycles. J Assist Reprod Genet 1997;14:32-34.

11 Faculty of Sexual and Reproductive Healthcare Clinical Effectiveness Unit. Intrauterine Contraception. 2007. http:// www.fsrh.org/pdfs/CEUGuidanceIntrauterineContraception Nov07.pdf [accessed 5 October 2012].

12 Lorusso F, Depalo R, Bettocchi S, et al. Outcome of in vitro fertilization after transabdominal ultrasound-assisted embryo transfer with a full or empty bladder. Fertil Steril 2005;84:1046-1048.

13 Robinson D, Cardozo L. Urinary incontinence (Chapter 51). In: Dewhurst's Textbook of Obstetrics and Gynaecology (8th edn). Chichester, UK: Wiley Blackwell, 2012;635-692.

14 Bongers MY, Mol BW, Brölmann HA. Prognostic factors for the success of thermal balloon ablation in the treatment of menorrhagia. Obstet Gynecol 2002;99:1060-1066.

15 Gervaise A, Fernandez H, Capella-Allouc S, et al. Thermal balloon ablation versus endometrial resection for the treatment of abnormal uterine bleeding. Hum Reprod 1999;14:27432747.

16 Wildermeersch D, Janssens D, Vrijens M, et al. Ease of insertion, contraceptive efficacy and safety of new T-shaped levonorgestrel-releasing intrauterine systems. Contraception 2005;71:465-469. 